\title{
Pharmacokinetic-Pharmacodynamic Profile, Bioavailability, and Withdrawal Time of Tylosin Tartrate Following a Single Intramuscular Administration in Olive Flounder (Paralichthys olivaceus)
}

\author{
Ji-Hoon Lee $\mathbb{1}$, Ga Won Kim, Mun-Gyeong Kwon and Jung Soo Seo *
}

\section{check for} updates

Citation: Lee, J.-H.; Kim, G.W.; Kwon, M.-G.; Seo, J.S.

Pharmacokinetic-Pharmacodynamic Profile, Bioavailability, and Withdrawal Time of Tylosin Tartrate Following a Single Intramuscular Administration in Olive Flounder (Paralichthys olivaceus). Animals 2021, 11, 2468. https://doi.org/10.3390/ ani11082468

Academic Editor: Lorenzo Fraile

Received: 3 August 2021

Accepted: 20 August 2021

Published: 23 August 2021

Publisher's Note: MDPI stays neutra with regard to jurisdictional claims in published maps and institutional affiliations.

Copyright: (c) 2021 by the authors. Licensee MDPI, Basel, Switzerland. This article is an open access article distributed under the terms and conditions of the Creative Commons Attribution (CC BY) license (https:/ / creativecommons.org/licenses/by/ $4.0 /)$.
Aquatic Disease Control Division, National Fisheries Products Quality Management Service, 216 Gijanghaean-ro, Gijang-eup, Gijang-gun, Busan 46083, Korea; jhlee001@korea.kr (J.-H.L.); gawon1020@korea.kr (G.W.K.); mgkwon@korea.kr (M.-G.K.)

* Correspondence: jsseosoo@korea.kr

Simple Summary: Fishes usually stop eating food when they are sick, and treating diseased fish with oral drugs is a serious hurdle in the aquaculture industry. Tylosin tartrate is a potent bacterial-killing agent useful against frequently occurring bacterial fish infections. We tested the effectiveness against pathogenic bacteria and the human safety of the drug for possible application to cultured olive flounder, one of the most important culture species in far eastern Asian countries. Tylosin tartrate was very effective in killing the pathogenic bacteria grown in artificial culture media, and it was also demonstrated that the drug reached body concentrations in olive flounder, high enough to kill the pathogen. In addition, we also determined how long to wait until the fish clears the injected drug out and it is possible for human consumption. These results will pave a new method for disease treatment useful for olive flounder farming.

\begin{abstract}
The objective of this study was to demonstrate the pharmacokinetic-pharmacodynamic profile, bioavailability, and withdrawal time of tylosin tartrate (TT) administered to olive flounder via intramuscular (IM, 10 or $20 \mathrm{mg} / \mathrm{kg}, n=240$ ) and intravascular (IV, $10 \mathrm{mg} / \mathrm{kg}, n=90)$ injections. Serum concentrations of tylosin were determined using a validated liquid chromatography-tandem mass spectrometry method. According to the non-compartmental analysis, the bioavailability of TT was $87 \%$. After the IV injection, the terminal half-life, total body clearance, volume of distribution, and mean residence time of TT were $21.07 \mathrm{~h}, 0.07 \mathrm{~L} / \mathrm{kg} / \mathrm{h}, 2.15 \mathrm{~L} / \mathrm{kg}$, and $16.39 \mathrm{~h}$, respectively. Rapid absorption ( $\mathrm{T}_{\max } 0.25 \mathrm{~h}$ ), prolonged action (terminal half-life, 33.96 and $26.04 \mathrm{~h}$; MRT, 43.66 and $33.09 \mathrm{~h}$ ), and linear dose-response relationship ( $\mathrm{AUC}_{0 \text {-inf }}, 123.55$ and $246.05 \mu \mathrm{g} / \mathrm{mL}^{*} \mathrm{~h}$ ) were monitored following 10 and $20 \mathrm{mg} / \mathrm{kg}$ IM injection. The withdrawal time of TT from muscle (water temperature, $22{ }^{\circ} \mathrm{C}$ ) was 9.84 days, rounded up to 10 days (220 degree days). Large $\mathrm{C}_{\max } / \mathrm{MIC}_{90}, \mathrm{AUC}_{0 \text {-inf }} / \mathrm{MIC}_{90}$, and $\mathrm{T}>\mathrm{MIC}_{90}$ values were obtained for Streptococcus isolates and these PK/PD indices satisfied the criteria required for efficacy evaluation. This study lays a foundation for the optimal use of TT and provides valuable information for establishing therapeutic regimens.
\end{abstract}

Keywords: bioavailability; olive flounder; pharmacokinetics; PK/PD; tylosin tartrate (TT); withdrawal time

\section{Introduction}

Antibiotics are typically administered to farmed fish via the oral route. However, the critical disadvantage of oral administration is the difficulty in administering the drug to a sick fish with a poor appetite [1]. Despite the other main disadvantages, such as high labor costs and tissue damage, one of the solutions to the low amount of drug intake is changing the drug from one that allows for oral administration to injection [2]. Olive 
flounder (Paralichthys olivaceus) typically remain calm during injection, so it can be treated without causing excessive stress. A few single and complex antibiotics that could be administered via injection, such as ampicillin, amoxicillin, ceftiofur, and the florfenicolamoxicillin combination, have been successfully implemented to treat $P$. olivaceus in the Korean aquaculture industry [3].

Tylosin tartrate (TT) is a macrolide antibiotic used in veterinary medicine and is extracted from the soil microbiome called Streptomyces fradiae [4]. It is a bacteriostatic antibiotic that binds to the 50S subunit of the bacterial ribosome and inhibits bacterial protein synthesis [5]. TT is known to be strongly effective against Gram-positive and mycoplasma bacteria [6]. To specify, it is broadly used to treat the following conditions: respiratory infection, mastitis, and arthritis in cows; atrophic rhinitis and dysentery in pigs; and mycoplasma infection in birds $[4,7,8]$.

A previous research study examined the efficacy and side effects of TT used to treat $P$. olivaceus infected with Streptococcus parauberis [9]. The administration of TT to P. olivaceus infected with $S$. parauberis intramuscularly (IM) yielded excellent results: a $90 \%$ relative survival rate and no hematological or histopathological side effects. These pharmacological characteristics of TT are beneficial in treating infections caused by Gram-positive bacteria, such as S. parauberis, in P. olivaceus.

TT distributes extensively in body fluids and tissues because of its high lipid solubility and $40 \%$ plasma protein binding $[10,11]$. The pharmacokinetic profile of TT has been evaluated in various livestock, such as pigs, cattle, chickens, ducks, sheep, and goats [12-18]. However, there is a lack of information on the pharmacokinetics, bioavailability, and tissue depletion of TT in fish, including P. olivaceus.

Moreover, most antimicrobial use in the global aquaculture industry is not related to classification of the target bacteria or susceptibility to the range of available antimicrobials [19], and the used dosage is often based on field results without scientific evidence rather than studies of the antibacterial activity (minimum inhibitory concentration, MIC) of antimicrobials [20]. For successful antimicrobial use in the field, the relationship between the serum levels of tylosin and observed efficacy, as well as the susceptibilities of the causative bacteria (MICs), must be established.

\section{Materials and Methods}

\subsection{Chemicals}

Analytical standard tylosin tartrate ( $\geq 98 \%$ ) was obtained from Dr. Ehrenstorfer $\mathrm{GmbH}$ (Augsburg, Germany). All primary analytical reagents for HPLC were purchased from Merck (Whitehouse Station, NJ, USA). All chemicals were of ACS grade purchased from the following sources: sodium phosphate dibasic $\left(\mathrm{Na}_{2} \mathrm{HPO}_{4}\right)$, sodium dihydrogen phosphate $\left(\mathrm{NaH}_{2} \mathrm{PO}_{4}\right)$, formic acid, and tricaine methanesulfonate (MS-222) from Sigma (St. Louis, MO, USA). The HLB Oasis column $(500 \mathrm{mg}, 6 \mathrm{~mL}$ ) purchased from Waters (Milford, MA, USA) was used for solid-phase extraction (SPE). Brain and heart infusion agar and MullerHinton broth were obtained from Difco (Sparks, MD, USA) and lysed horse blood was obtained from Oxoid (Basingstoke, Hampshire, UK). Parenteral TT injection formulation (Tylosin tartrate, injection, $200 \mathrm{mg} / \mathrm{mL}$ injectable solution) was purchased from Eeglevet Veterinary Medicine Co., LTD. (Yesan, Chungnam-do, Korea) and diluted with phosphatebuffered physiological saline.

\subsection{Animals}

Healthy P. olivaceus weighing $122.9 \pm 10.7 \mathrm{~g}$ were obtained from a farm located in Pohang, Gyeongsangbukdo. Fish were allowed to adapt to the laboratory conditions for 2 weeks. During this time, they were stored in three circular PVC fish water tanks of $3.0 \mathrm{~m}(\mathrm{~L}) \times 3.0 \mathrm{~m}(\mathrm{~W}) \times 1.0 \mathrm{~m}(\mathrm{H})$ in size and fed $1 \%$ of their body weight with commercial pellet feeds (CJ Feed, Gunsan, Jeonbuk, Korea) per day. Water quality was checked at 09:00 am every day and maintained at approximately $30 \mathrm{PSU}, 7-8 \mathrm{mg} / \mathrm{L}$ of dissolved oxygen, $\mathrm{pH} 8.1$, and temperature of $22 \pm 0.5^{\circ} \mathrm{C}$. All fish were fasted before the experiment 
to avoid potential adverse effects caused by residual food in their gastrointestinal tract. They were weighed and administered doses based on their body weight. This study followed the protocol approved by the Institutional Animal Care and Use Committee (IACUC, Fish Study Protocol NIFS-2019-3) from the National Institute of Fisheries Science (NIFS). No fish died during the adaptation and sampling period. The absence of tylosin in the muscle and serum was confirmed in five fish before commencement of the experiments.

\subsection{Experimental Design}

The fish were divided into three groups: pharmacokinetic, bioavailability, and tissue depletion group, with 180 (IM dose of 10 and $20 \mathrm{mg} / \mathrm{kg}, n=90$, each group), 90 (IV dose of $10 \mathrm{mg} / \mathrm{kg}$ ), and 60 (IM dose of $10 \mathrm{mg} / \mathrm{kg}$ ) fish in each.

Single IM injections of TT were administered into the thick and muscular area under the dorsal fin at 10 and $20 \mathrm{mg} / \mathrm{kg}$ to fish maintained at $22 \pm 0.5{ }^{\circ} \mathrm{C}(n=10$, each time point) in the pharmacokinetic study. The chosen dose was $10 \mathrm{mg} / \mathrm{kg}$ TT because a previous pilot study showed that a single IM injection of TT was effective in combating bacterial infections, such as S. parauberis [9]. We also selected double doses $(20 \mathrm{mg} / \mathrm{kg})$ to determine if IM administered TT comply with a dose-proportional relationship for the pharmacokinetic parameters, so that it could support extrapolation of the dose levels based on the susceptibility of organisms.

For single IV injection, TT was injected into the caudal vein as a single bolus at $10 \mathrm{mg} / \mathrm{kg}$ for bioavailability studies. The location of the needle in the caudal vein was confirmed by aspirating a small amount of blood before injection. Fish injured during the procedure due to excessive bleeding were replaced with new fish.

Ten fish from each group were sampled at $0.25,0.5,1,3,6,12,24,48$, and $72 \mathrm{~h}$ after drug administration. To collect blood samples, fish were anesthetized with a light MS-222 aesthetic at a dose of approximately $20 \mathrm{mg} / \mathrm{L}$. Blood samples $(1.5 \mathrm{~mL})$ were obtained from the caudal vein using a $1-\mathrm{mL}$ syringe and transferred to a serum separator tube (SST). The blood samples were centrifuged at $3000 \times \mathrm{g}$ for $10 \mathrm{~min}$ at $4{ }^{\circ} \mathrm{C}$. Isolated serum was preserved at $-80^{\circ} \mathrm{C}$ to analyze the drug concentration and determine the pharmacokinetic parameters.

Tissue depletion studies of the withdrawal time were performed in fish maintained as described above. Fish were single-IM injected with $10 \mathrm{mg} / \mathrm{kg}$ TT. Muscle samples were obtained 1, 2, 3, 4, 5, and 7 days following the end of the last administration. Muscles were sampled and stored at $-80^{\circ} \mathrm{C}$ pending analysis for the residue depletion test.

\subsection{Sample Preparation and HPLC-MS/MS Analysis}

The serum or muscle TT concentration was measured using a modified high-performance liquid chromatography-tandem mass spectrometry (HPLC-MS/MS) described in the Korean Food Standards Codex [21]. To simplify, serum or muscle samples $(0.5 \mathrm{~mL}$ or $2 \mathrm{~g}$, respectively) were homogenized in $6 \mathrm{~mL}$ of methanol and centrifuged at $3000 \times g$ for $10 \mathrm{~min}$ for extraction. The clear supernatant was transferred to a $15-\mathrm{mL}$ conical polypropylene tube and the extract was evaporated in a stream of nitrogen at $50{ }^{\circ} \mathrm{C} . \mathrm{Na}_{2} \mathrm{HPO}_{4}-\mathrm{NaH}_{2} \mathrm{PO}_{4}$ ( $3 \mathrm{~mL}, 0.2 \mathrm{M}, \mathrm{pH} 7.2$ ) was added to the residue. The mixture was loaded onto methanolwater pre-activated ( $5 \mathrm{~mL}$ pre-rinsing) HLB cartridge columns, flushed with $5 \mathrm{~mL}$ of $5 \%$ aqueous methanol, and eluted with $5 \mathrm{~mL}$ of methanol. The eluted extract was evaporated in a stream of nitrogen at $50^{\circ} \mathrm{C}$. The residue was reconstituted with $1 \mathrm{~mL}$ of HPLC-grade methanol:water (1:1) and filtered using $0.2-\mu \mathrm{m}$ syringe filters; $10 \mu \mathrm{L}$ of the residue were analyzed using the HPLC-MS/MS system.

The HPLC-MS/MS system consists of an Agilent 1260 Infinity series LC (Agilent Technologies, Santa Clara, CA, USA) combined with an Agilent 6430 Triple Quad detector. Chromatography separation was performed using a $\mathrm{C}_{18}$ reverse-phase $1.8-\mu \mathrm{m}$ Agilent Zorbax RRHD SB column $(2.1 \times 50 \mathrm{~mm})$, which can be maintained at a temperature of $40{ }^{\circ} \mathrm{C}$. During the mobile phase, isocratic elution was performed using the mixture of acetonitrile:water $(7: 3)$ containing $0.1 \%$ formic acid at a flow rate of $0.25 \mathrm{~mL} / \mathrm{min}$. an 
MS/MS detector was used using the following parameter settings: capillary voltage at $4000 \mathrm{~V}$; nebulizer gas $\left(\mathrm{N}_{2}\right)$; nebulizer gas flow at $11 \mathrm{~L} / \mathrm{min}$; nebulizer pressure at $45 \mathrm{psi}$; gas temperature at $350{ }^{\circ} \mathrm{C}$; and delta $\mathrm{EMV}^{+}$at $500 \mathrm{~V}$. TT was evaluated in multiple-reaction monitoring mode for positive charges. Quantification and qualification ions were $m / z$ 916.5 to174.1 and from $m / z 916.5$ to 101.1 , respectively.

The analytical method was validated according to the criteria of the validation procedure [22]. Linearity was evaluated using matrix-matched calibration (MMC) by spiking extracted blanks at four concentration levels $(0.5,1,10$, and $50 \mathrm{ng} / \mathrm{g}(\mathrm{mL}))$. The calculated regression lines with standard solutions rendered perfect fits of $\mathrm{r}^{2}>0.99$. Limit values of detection (LOD) and quantification (LOQ) were determined from signal-to-noise (S/N) ratios of 3:1 and 10:1, respectively. Recovery rates for the extraction procedure from olive flounder tissues were determined by spiking known concentrations of standard solution at three levels $(0.5,5$, and $50 \mathrm{ng} / \mathrm{g}(\mathrm{mL}))$ into serum or muscle samples. In addition, to avoid the influence of variable instrument sensitivity over time, the linearity of the standard curves for spiked TT standards was checked at the beginning and end to ensure absence of significant fluctuations.

\subsection{Pharmacokinetic Analysis}

The pharmacokinetic parameters for serum concentration were analyzed based on the non-compartmental analysis model using the PKSolver, an add-in program for Microsoft Excel [23]. The peak serum concentration $\left(C_{\max }\right)$ and time to peak serum concentration $\left(\mathrm{T}_{\max }\right)$ were determined directly from the experimental data. The area under the concentration-time curve (AUC) was determined by the trapezoidal rule. Bioavailability $(F)$ was calculated as $F(\mathrm{IM})=100 \times\left(\mathrm{AUC}_{\mathrm{IM}} \times\right.$ dose $\left._{\mathrm{IV}}\right) /\left(\mathrm{AUC}_{\mathrm{IV}} \times\right.$ dose $\left._{\mathrm{IM}}\right)$.

\subsection{In Vitro Antibacterial Activity}

In vitro antibacterial activity tests were performed in accordance with the CLSI guideline explained for MIC tests [24]. Bacteria isolated from fish farms in Korea were used for MIC tests, and their detailed strain information is presented in Table 3. Bacteria were incubated at $28^{\circ} \mathrm{C}$ in brain-heart infusion agar (BHIA) for $24 \mathrm{~h}$, and their colonies were inoculated to Mueller-Hinton broth (MHB) consisting of 5\% horse blood lysates for a 24-h incubation at $28^{\circ} \mathrm{C}$. The test drug TT was serially diluted in 96-well plates consisting of MHB to determine MIC via protocol, described in the VET04-A2. Bacteria were loaded at a density of $5 \times 10^{5}$ colony-forming units (CFU) $/ \mathrm{mL}$ and cultured at $28^{\circ} \mathrm{C}$ for $24 \mathrm{~h}$. The MIC was determined as the lowest antibiotic concentration at which bacterial growth was visibly inhibited. The quality control was performed using Escherichia coli ATCC 25922/NCIMB11210; Aeromonas salmonicida subsp. ATCC 33658/NCIMB1102; and Staphylococcus aureus ATCC 25923 for the precision and accuracy of the test.

\subsection{Pharmacokinetic (PK)/Pharmacodynamic (PD) Relationships}

Surrogate markers for antibacterial efficacy, including the peak serum concentration $\left(\mathrm{C}_{\max }\right) / \mathrm{MIC}$, area under the concentration-time curve (AUC)/MIC, and the duration of time (T > MIC) over MIC, were determined using in vitro MIC data and in vivo PK parameters obtained following IM injection of TT at 10 and $20 \mathrm{mg} / \mathrm{kg}$ to olive flounder [2,25,26].

\subsection{Withdrawal Period Calculation}

The calculation of the withdrawal time (WT) was performed in accordance with the muscle drug concentration by applying a method developed by the Committee for Veterinary Medicinal Products [27]. The mathematical program used for statistical analysis was WT 1.4 software [28], and the log-linear transformed muscle drug concentration was used as data. Cut-off points were estimated from the upper $95 \%$ or $99 \%$ at the $95 \%$ confidence limit by applying a maximum residue level (MRL) of $0.1 \mu \mathrm{g} / \mathrm{g}$ for tylosin in fin fish muscle [29]. 


\section{Results}

\subsection{Analytical Method Validation}

An HPLC-MS/MS analysis was used to validate a $0.5 \mathrm{ng} / \mathrm{mL}$ limit of quantification used. The retention time of tylosin in the serum was found to be about $0.6 \mathrm{~min}$ (Figure 1). The linearity showed a strong linear regression for the MMC (regression line: $\mathrm{y}=976.11 \mathrm{x}-340.27$; correlation coefficient, $\left.\mathrm{r}^{2}=0.999\right)$ range of $0.5-50 \mathrm{ng} / \mathrm{mL}$. The interday and intra-day precision (coefficient of variance) were below $12.8 \%$ for three concentrations: $0.5,5$, and $50 \mathrm{ng} / \mathrm{mL}$. The accuracy (recovery rate) ranged from $83.2 \%$ to $103.0 \%$, satisfying the criteria of the Bioanalytical Method Validation Guidance for Industry [30]. Details on the parameters are presented in Table 1.

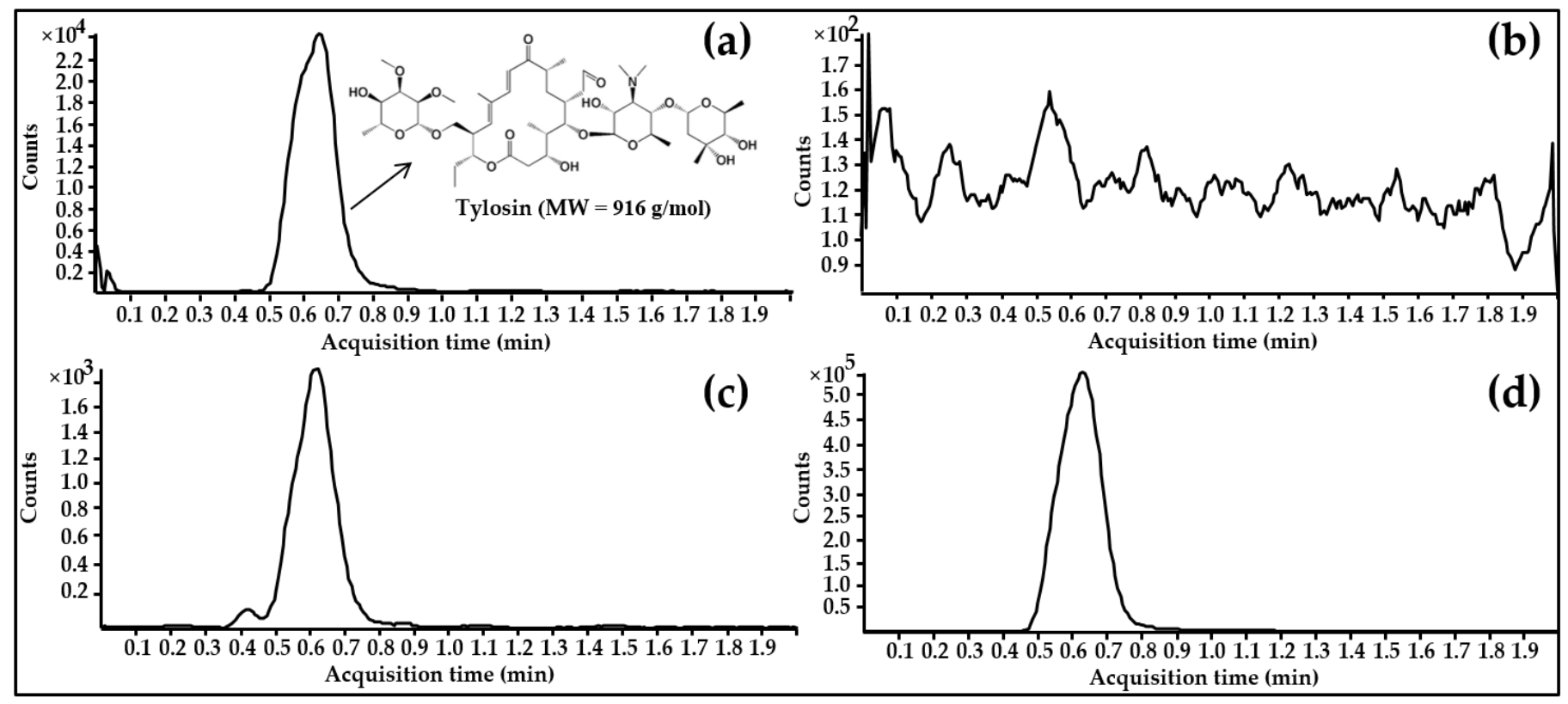

Figure 1. Total ion chromatograms: (a) standard solution at $50 \mathrm{ng} / \mathrm{mL}$; (b) blank serum sample; (c) blank serum sample spiked with tylosin at $10 \mathrm{ng} / \mathrm{mL}$; (d) serum sample at $1 \mathrm{~h}$ after intramuscular administration of tylosin tartrate.

Table 1. Validation parameter for the determination of tylosin in olive flounder serum and muscle concentration analysis using HPLC-MS/MS.

\begin{tabular}{|c|c|c|c|c|c|c|c|c|c|}
\hline \multirow[b]{2}{*}{ Analyte } & \multirow[b]{2}{*}{ Matrix } & \multirow{2}{*}{$\begin{array}{l}\text { Spike } \\
\text { Level } \\
\text { (ng/g) }\end{array}$} & \multirow{2}{*}{$\begin{array}{c}\text { Measured } \\
\text { Concentration } 1 \\
(\mathrm{ng} / \mathrm{g})\end{array}$} & \multicolumn{2}{|c|}{ Intra-Day $(n=3)$} & \multicolumn{2}{|c|}{ Inter-Day $(n=9)$} & \multirow[b]{2}{*}{$\begin{array}{l}\text { LOD } \\
(\mathrm{ng} / \mathrm{g})\end{array}$} & \multirow[b]{2}{*}{$\begin{array}{c}\mathrm{LOQ}^{3} \\
\text { (ng/g) }\end{array}$} \\
\hline & & & & $\begin{array}{c}\text { Accuracy } \\
(\%)\end{array}$ & $\begin{array}{c}\text { Precision }{ }^{2} \\
(\%)\end{array}$ & $\begin{array}{c}\text { Accuracy } \\
(\%)\end{array}$ & $\begin{array}{l}\text { Precision } \\
\text { (\%) }\end{array}$ & & \\
\hline \multirow{6}{*}{ Tylosin } & & 0.5 & 0.46 & 103.0 & 5.0 & 89.6 & 11.7 & \multirow{3}{*}{0.25} & \multirow{3}{*}{0.5} \\
\hline & Serum & 5 & 4.21 & 83.2 & 2.3 & 84.5 & 8.3 & & \\
\hline & & 50 & 44.20 & 94.5 & 3.6 & 86.4 & 3.5 & & \\
\hline & \multirow{3}{*}{ Muscle } & 0.5 & 0.45 & 93.7 & 11.6 & 89.5 & 12.8 & \multirow{3}{*}{0.25} & \multirow{3}{*}{0.5} \\
\hline & & 5 & 4.58 & 89.5 & 8.8 & 92.3 & 9.0 & & \\
\hline & & 50 & 45.28 & 91.6 & 8.4 & 90.2 & 9.3 & & \\
\hline
\end{tabular}

${ }^{1}$ Data are expressed as mean from 12 samples. ${ }^{2}$ Precision (relative standard deviations, RSDs) must be $<20 \%$ compliance with the European Commission [22]. ${ }^{3}$ LOQs were lower than the reported MRLs set by the Committee for Veterinary Medicinal Products [29] for fin fish muscle.

\subsection{Serum Pharmacokinetics}

All fish tolerated TT administered by IM or IV injection well, and no adverse effects were noted. Figure 2 illustrates the semilogarithmic plot of the serum tylosin concentrationtime profile following single IM injection at 10 and $20 \mathrm{mg} / \mathrm{kg}$. Tylosin was continuously detected up to $72 \mathrm{~h}$ after administration. Table 2 shows the major pharmacokinetic parameters and $F$ of tylosin based on the noncompartmental analysis model. After the IV injection, 
the terminal half-life $\left(\mathrm{t}_{1 / 2} \lambda_{\mathrm{z}}\right)$, total body clearance $(\mathrm{Cl})$, volume of distribution $\left(\mathrm{V}_{\mathrm{z}}\right)$, and the mean residence time (MRT) of TT were $21.07 \mathrm{~h}, 0.07 \mathrm{~L} / \mathrm{kg} / \mathrm{h}, 2.15 \mathrm{~L} / \mathrm{kg}$, and $16.39 \mathrm{~h}$, respectively. After the IM injection, $C_{\max }$ was 10.76 and $16.60 \mu \mathrm{g} / \mathrm{mL}$, and it took $0.25 \mathrm{~h}$ $\left(\mathrm{T}_{\max }\right)$ after the administration to reach $\mathrm{C}_{\max }$, at doses of 10 and $20 \mathrm{mg} / \mathrm{kg}$, respectively. The extent of TT absorption indicated the linear dose-response relationship with AUC following $10 \mathrm{mg} / \mathrm{kg}$ IM injection $\left(123.55 \mu \mathrm{g} / \mathrm{mL}^{*} \mathrm{~h}\right)$ proportionally increased the $246.05 \mu \mathrm{g} / \mathrm{mL}{ }^{*} \mathrm{~h}$ at $20 \mathrm{mg} / \mathrm{kg}$. The $t_{1 / 2} \lambda_{z}$ and MRT of $10 \mathrm{mg} / \mathrm{kg}$ IM injection were 33.96 and $43.66 \mathrm{~h}$, respectively. For the $20 \mathrm{mg} / \mathrm{kg}$ IM injection, $\mathrm{t}_{1 / 2} \lambda_{\mathrm{z}}$ and MRT were 26.04 and $33.09 \mathrm{~h}$, respectively. The TT bioavailability after IM injection was 86.98 to $87.32 \%$. Detailed pharmacokinetic parameters are given in Table 2.

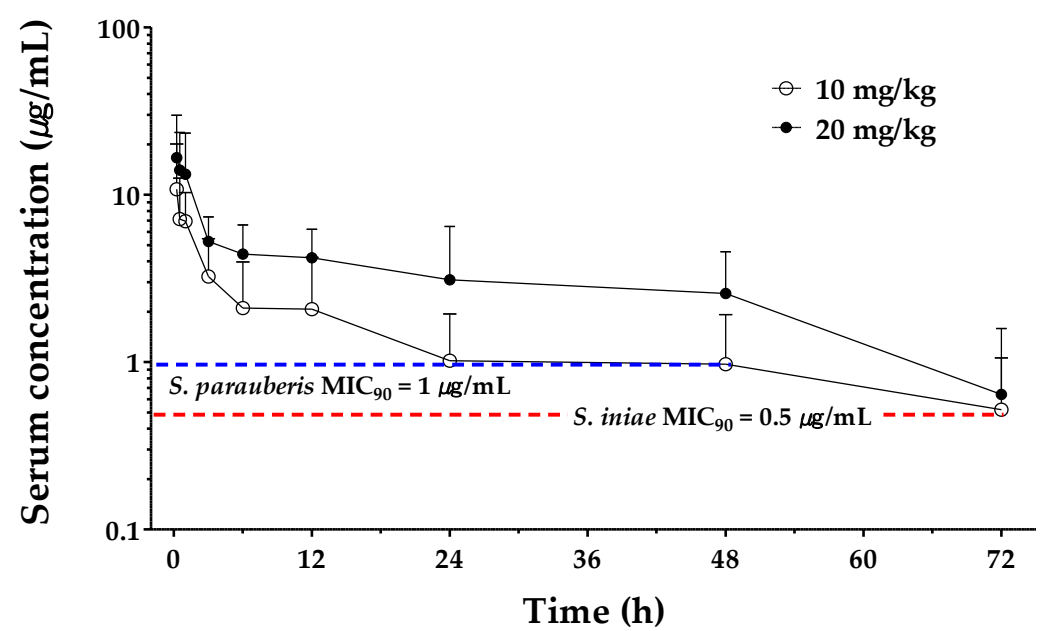

Figure 2. A semilogarithmic plot of the tylosin concentration-time profile in serum following a single intramuscular administration at 10 and $20 \mathrm{mg} / \mathrm{kg}$. Data are expressed as mean $\pm \mathrm{SD}$ from 10 olive flounders at each time point. The minimum inhibitory concentration (MIC) value corresponds to Streptococcus parauberis $\mathrm{MIC}_{90}(1 \mu \mathrm{g} / \mathrm{mL})$ and S. iniae $\mathrm{MIC}_{90}(0.5 \mu \mathrm{g} / \mathrm{mL})$.

Table 2. Pharmacokinetic parameters of tylosin tartrate following a single intramuscular and intravenous administration to olive flounder.

\begin{tabular}{|c|c|c|c|c|}
\hline \multirow{2}{*}{ Parameter } & \multirow{2}{*}{ Unit } & \multicolumn{3}{|c|}{ Single Dose of Tylosin Tartrate } \\
\hline & & IV $10 \mathrm{mg} / \mathrm{kg}$ & IM $10 \mathrm{mg} / \mathrm{kg}$ & IM $20 \mathrm{mg} / \mathrm{kg}$ \\
\hline$\lambda_{\mathrm{z}}$ & $1 / \mathrm{h}$ & 0.03 & 0.02 & 0.03 \\
\hline$t_{1 / 2} \lambda_{z}$ & $\mathrm{~h}$ & 21.07 & 33.96 & 26.04 \\
\hline $\mathrm{T}_{\max }$ & $\mathrm{h}$ & NA & 0.25 & 0.25 \\
\hline $\mathrm{C}_{\max }$ & $\mu \mathrm{g} / \mathrm{mL}$ & NA & 10.76 & 16.60 \\
\hline $\mathrm{AUC}_{0-\mathrm{t}}$ & $\mu \mathrm{g} / \mathrm{mL}^{*} \mathrm{~h}$ & 133.63 & 98.20 & 221.83 \\
\hline $\mathrm{AUC}_{0 \text {-inf }}$ & $\mu \mathrm{g} / \mathrm{mL}^{*} \mathrm{~h}$ & 141.44 & 123.55 & 246.05 \\
\hline AUMC $_{0 \text {-inf }}$ & $\mu \mathrm{g} / \mathrm{mL}^{*} \mathrm{~h}^{2}$ & 2318.13 & 5393.46 & 8142.39 \\
\hline MRT & $\mathrm{h}$ & 16.39 & 43.66 & 33.09 \\
\hline $\mathrm{V}_{\mathrm{Z}}$ & $\mathrm{L} / \mathrm{kg}$ & 2.15 & - & - \\
\hline $\mathrm{Cl}$ & $\mathrm{L} / \mathrm{kg} / \mathrm{h}$ & 0.07 & - & - \\
\hline$F$ & $\%$ & - & 87.35 & 86.98 \\
\hline
\end{tabular}

Data are expressed as the mean from 10 olive flounders. $\lambda_{z}$, first-order rate constant associated with the terminal portion of the curve; $t_{1 / 2} \lambda_{z}$, terminal half-life; $T_{\max }$, time to peak serum concentration; $C_{\max }$, peak serum concentration; $\mathrm{AUC}_{0-\mathrm{t}}$, area under the concentration-time curve from time zero to time $\mathrm{t} ; \mathrm{AUC}_{0 \text {-inf, }}$ area under the concentration-time curve from zero to time infinity; AUMC, area under the first moment curve; MRT, mean residence time; $\mathrm{V}_{\mathrm{z}}$, apparent volume of distribution; $\mathrm{Cl}$, total body clearance; $F$, systemic bioavailability; $\mathrm{NA}$, not applicable; IV, intravenous; IM, intramuscular. 


\subsection{MIC Determination of Clinical Streptococcus Isolates}

The MICs of 43 clinical Streptococcus isolates are shown in Table 3. Twenty-three S. iniae strains showed an MIC range between 0.125 and $0.5 \mu \mathrm{g} / \mathrm{mL}$. Twenty S. parauberis strains showed an MIC range between 0.5 and $2 \mu \mathrm{g} / \mathrm{mL}$.

Table 3. In vitro antibacterial activity minimum inhibitory concentrations (MICs) tylosin tartrate against S. iniae and S. parauberis.

\begin{tabular}{|c|c|c|c|}
\hline Bacterium Name & $\begin{array}{l}\text { Isolation Sources } \\
\text { (Number of Strains) }\end{array}$ & Strain Codes & $\operatorname{MIC}(\mu \mathrm{g} / \mathrm{mL})$ \\
\hline \multirow{22}{*}{ Streptococcus iniae } & Busan, olive flounder, $2004(n=1)$ & FP2140 & 0.5 \\
\hline & \multirow{2}{*}{ Jeju, olive flounder, $2004(n=2)$} & FP2149 & 0.125 \\
\hline & & FP2150 & 0.25 \\
\hline & Ulsan, olive flounder, $2004(n=1)$ & FP3060 & 0.25 \\
\hline & Tongyeong, rock bream, $2006(n=1)$ & FP3187 & 0.25 \\
\hline & Pohang, olive flounder, $2007(n=1)$ & FP3358 & 0.125 \\
\hline & Taean, rock fish, $2008(n=1)$ & FP3476 & 0.25 \\
\hline & \multirow{4}{*}{ Jeju, olive flounder, $2004(n=4)$} & FP4033 & 0.25 \\
\hline & & FP4143 & 0.5 \\
\hline & & FP4160 & 0.125 \\
\hline & & FP4164 & 0.25 \\
\hline & Wando, olive flounder, $2004(n=1)$ & FP4080 & 0.25 \\
\hline & Ulsan, olive flounder, $2005(n=1)$ & FP5162 & 0.25 \\
\hline & Jeju, olive flounder, $2006(n=1)$ & FP6085 & 0.125 \\
\hline & Tongyeong, rock fish, $2012(n=1)$ & FPa4413 & 0.125 \\
\hline & Tongyeong, olive flounder, $1998(n=1)$ & BS9 & 0.25 \\
\hline & Yeosu, rainbow fish, $2010(n=1)$ & RaB6-1-a & 0.25 \\
\hline & Yeosu, saddled weever, $2010(n=1)$ & SW9-2-a-an & 0.5 \\
\hline & Yeosu, stripey, $2010(n=1)$ & st11-1-b-an & 0.5 \\
\hline & \multirow{3}{*}{$\begin{array}{l}\text { Gyeongsangbukdo, olive flounder, } \\
\qquad 2003(n=4)\end{array}$} & A11022 & 0.125 \\
\hline & & A11024, A11025 & 0.25 \\
\hline & & A11023 & 0.5 \\
\hline \multirow{10}{*}{ Streptococcus parauberis } & \multirow{2}{*}{ Jeju, olive flounder, $2003(n=2)$} & KSP1 & 0.5 \\
\hline & & KSP4 & 1 \\
\hline & \multirow{2}{*}{ Jeju, olive flounder, $2004(n=3)$} & KSP5, KSP10 & 0.5 \\
\hline & & KSP6 & 1 \\
\hline & Jeju, olive flounder, $2005(n=2)$ & KSP14, KSP20 & 1 \\
\hline & Haenam, olive flounder, $2005(n=1)$ & KSP22 & 2 \\
\hline & \multirow{2}{*}{ Wando, olive flounder, $2005(n=2)$} & KSP40 & 1 \\
\hline & & KSP24 & 2 \\
\hline & Jeju, olive flounder, $1999(n=1)$ & KSP45 & 1 \\
\hline & Jeju, olive flounder, $2018(n=9)$ & $\begin{array}{l}\text { SPOF18J1, SPOF18J3, } \\
\text { SPOF18J4, SPOF18J5, } \\
\text { SPOF18J6, SPOF18J7, } \\
\text { SPOF18J9, SPOF18J10, } \\
\text { SPOF18J11 }\end{array}$ & 1 \\
\hline
\end{tabular}




\subsection{PK/PD Relationships}

The MICs of TT that restrained 50 and $90 \%$ of the clinical Streptococcus isolates (MIC $_{50}$ and $\mathrm{MIC}_{90}$ ) are shown in Table 4. Its values were integrated based on the serum concentration in the PK data to determine the $\mathrm{C}_{\max } / \mathrm{MIC}, \mathrm{AUC} / \mathrm{MIC}$, and $\mathrm{T}>\mathrm{MIC}$ ratios. According to Table 4, S. iniae and S. parauberis were calculated with large $C_{\max } / \mathrm{MIC}$ and AUC/MIC values. Moreover, T > MIC was maintained for at least about 2 days, with serum concentrations exceeding the MIC for both strains.

Table 4. Pharmacokinetic-pharmacodynamic (PK/PD) integration of tylosin tartrate based on pharmacokinetic data in olive flounder and in vitro MICs.

\begin{tabular}{|c|c|c|c|c|}
\hline Bacterial Strain $^{1}$ & S. iniae & S. parauberis & S. iniae & S. parauberis \\
\hline \multicolumn{5}{|l|}{$\operatorname{MIC}^{2}(\mu \mathrm{g} / \mathrm{mL})$} \\
\hline Range & $0.125-0.5$ & $0.5-2$ & $0.125-0.5$ & $0.5-2$ \\
\hline $\mathrm{MIC}_{50}$ & 0.25 & 1 & 0.25 & 1 \\
\hline $\mathrm{MIC}_{90}$ & 0.5 & 1 & 0.5 & 1 \\
\hline $\mathrm{TT}^{3}$ doses $(\mathrm{mg} / \mathrm{kg}, \mathrm{IM})$ & \multicolumn{2}{|c|}{$10 \mathrm{mg} / \mathrm{kg}$} & \multicolumn{2}{|c|}{$20 \mathrm{mg} / \mathrm{kg}$} \\
\hline $\mathrm{C}_{\max } / \mathrm{MIC}_{50}$ & 43.04 & 10.76 & 66.40 & 16.60 \\
\hline $\mathrm{C}_{\max } / \mathrm{MIC}_{90}$ & 21.52 & 10.76 & 33.20 & 16.60 \\
\hline $\mathrm{AUC}_{0-\mathrm{t}} / \mathrm{MIC}_{50}(\mathrm{~h})$ & 392.80 & 98.20 & 887.32 & 221.83 \\
\hline $\mathrm{AUC}_{0-\mathrm{t}} / \mathrm{MIC}_{90}(\mathrm{~h})$ & 196.40 & 98.20 & 443.66 & 221.83 \\
\hline $\mathrm{AUC}_{0 \text {-inf }} / \mathrm{MIC}_{50}(\mathrm{~h})$ & 494.20 & 123.55 & 984.20 & 246.05 \\
\hline $\mathrm{AUC}_{0 \text {-inf }} / \mathrm{MIC}_{90}(\mathrm{~h})$ & 247.10 & 123.55 & 492.10 & 246.05 \\
\hline $\mathrm{T}>\mathrm{MIC}_{50}(\mathrm{~h})$ & 84.36 & 44.75 & 101.71 & 62.66 \\
\hline $\mathrm{T}>\mathrm{MIC}_{90}(\mathrm{~h})$ & 64.56 & 44.75 & 81.92 & 62.66 \\
\hline
\end{tabular}

${ }^{1}$ Twenty-three test strains of Streptococcus iniae and 20 test strains S. parauberis. ${ }^{2}$ MIC, minimum inhibitory concentration. ${ }^{3}$ TT, tylosin tartrate.

\subsection{Muscle Withdrawal Time}

The residue depletion of tylosin from muscle was monitored after TT single injection at $10 \mathrm{mg} / \mathrm{kg}$, and the results as a function of time are shown in Figure 3 . The muscle concentrations sampled 1, 2, 3, 4, 5, and 7 days following a single IM injection at $10 \mathrm{mg} / \mathrm{kg}$ were used, where the average concentrations of tylosin were $0.83,0.66,0.60,0.23,0.22$, and $0.08 \mu \mathrm{g} / \mathrm{g}$, respectively. Withdrawal times were estimated by applying an official MRL of $0.1 \mu \mathrm{g} / \mathrm{g}$. The calculated withdrawal times of TT were 8.94 days (95\% statistical tolerance limit, Figure 3a) or 9.84 days (99\% statistical tolerance limit, Figure 3b), which has been rounded up to 10 days $(99 \%)$.

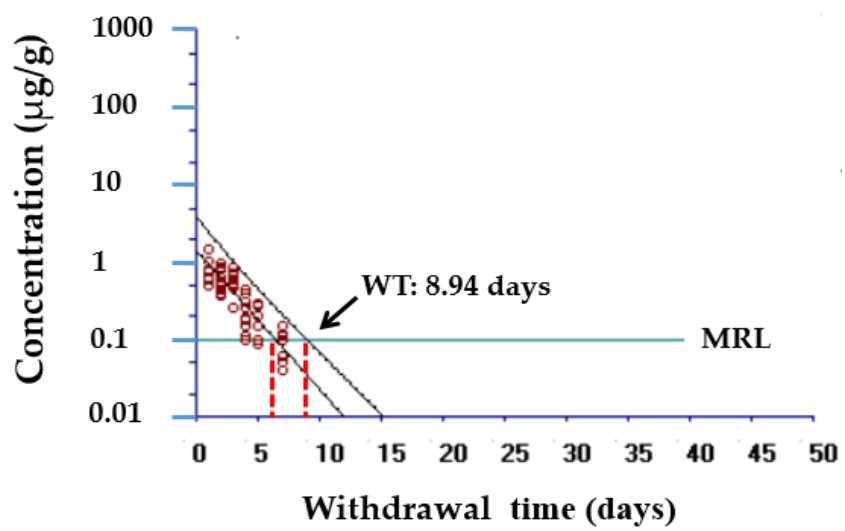

(a)

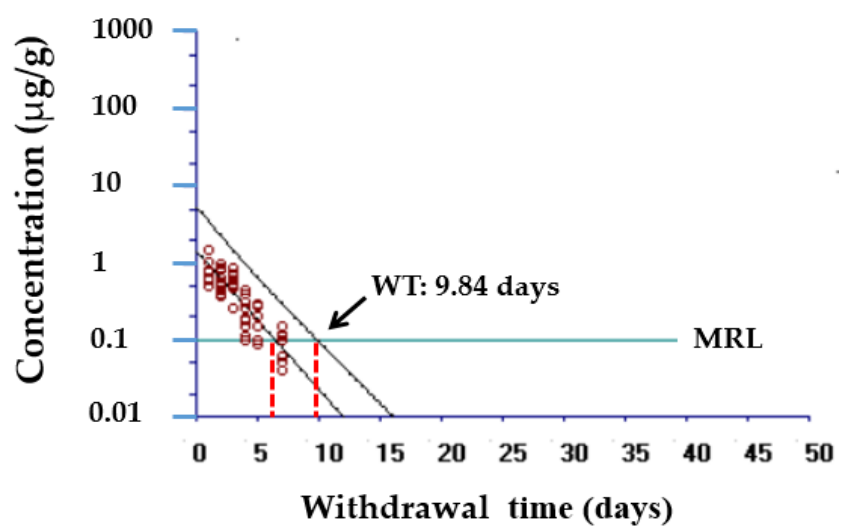

(b)

Figure 3. Residue depletion of tylosin from muscle after a single intramuscular administration of $10 \mathrm{mg} / \mathrm{kg}$ tylosin tartrate for 1 week: (a) 95\% statistical tolerance limit with 95\% confidence; (b) 99\% statistical tolerance limit with $95 \%$ confidence. Data are expressed from 10 olive flounders at each time point. The maximum residue limit (MRL) used was an official level of $0.1 \mu \mathrm{g} / \mathrm{g}$. 


\section{Discussion}

To the best of the authors' knowledge, this is the first study describing the pharmacokinetic profile of TT in fish including P. olivaceus. Our study provides meaningful pharmacokinetic results of injectable TT in olive flounder, which, in relation to the absorption of TT, is quite rapid from the IM site, showing a long $t_{1 / 2} \lambda_{z}$ and MRT is beneficial for efficacy, and a linear dose-response relationship with AUC. In addition, by providing a degree day through muscle residue analysis, it was demonstrated that TT is an appropriate drug for treating fish for food.

The dose of IM injection in the pharmacokinetic study was set at $10 \mathrm{mg} / \mathrm{kg}$ based on a previous pilot study. Although the pharmacokinetic parameter of IV administration to cultured fish is not important in the application to real practice, it is necessary to calculate the $F$ of other routes of administration, such as oral and IM injection. The dose of IV injection was set at $10 \mathrm{mg} / \mathrm{kg}$ to calculate factors, such as $F$ or $\mathrm{V}_{\mathrm{z}}$.

The $t_{1 / 2} \lambda_{z}$ after IV injection was $21.07 \mathrm{~h}$, indicating that the rate of drug elimination is relatively slow in P. olivaceus, possibly due to differences between species. Fish have a lower metabolic rate than mammals $\left(\mathrm{t}_{1 / 2}=4.52 \mathrm{~h}\right)$ [16] and birds $\left(\mathrm{t}_{1 / 2}=2.04 \mathrm{~h}\right)$ [14], which explains the low elimination rate of TT in P. olivaceus. $\mathrm{V}_{\mathrm{z}}$ represents the volume of distribution to body tissues and fluids, and this was high in P. olivaceus $(2.15 \mathrm{~L} / \mathrm{kg})$. The high $V_{z}$ of TT observed in the present study suggests a high volume of distribution to body tissues of P. olivaceus, supported by the results of a previous study in which $\mathrm{V}_{\mathrm{z}}$ higher than $1 \mathrm{~L} / \mathrm{kg}$ defined the high volume of distribution of the drug [31]. The extensive distribution of TT throughout the body can be attributed to high lipid solubility and moderate plasma protein binding [14]. Overall, the data suggest that TT has a long half-life and is widely distributed in P. olivaceus.

After IM injection at $10 \mathrm{mg} / \mathrm{kg}$, TT reached a $\mathrm{C}_{\max }$ of $10.76 \mu \mathrm{g} / \mathrm{mL}$ at $0.25 \mathrm{~h}\left(\mathrm{~T}_{\max }\right)$, after being rapidly absorbed into the serum. Although the information about pharmacokinetics of TT after IM injection in other fish may not be applicable to this study, the rapid rate of absorption was similar to the values reported ( $T_{\max }$ within $1 \mathrm{~h}$ ) in ducks, cattle, buffaloes, and sheep $[14,17,32]$. The dose-normalized exposure (AUC) in olive flounder $(123.5 \mu \mathrm{g} / \mathrm{mL} * \mathrm{~h}$ at $10 \mathrm{mg} / \mathrm{kg})$ was 32 -fold greater than the one found in the previous study (duck) that used intramuscular administration of the TT $(19.14 \mu \mathrm{g} / \mathrm{mL}$ 'h after $50 \mathrm{mg} / \mathrm{kg}$ ) [14], which prolonged the duration of action as evidenced by the large exposure (AUC). The $F$ of TT was calculated to be $87.35 \%$ in P. olivaceus after IM injection at $10 \mathrm{mg} / \mathrm{kg}$, supporting the rapid and nearly complete absorption following IM administration. The comparative pharmacokinetic parameters for the administered dose all showed a fast absorption rate $\left(T_{\max }, 0.25 \mathrm{~h}\right.$ ), and when administered at $20 \mathrm{mg} / \mathrm{kg}$ rather than $10 \mathrm{mg} / \mathrm{kg}$, the $\mathrm{C}_{\max }$ was absorbed 1.5 times higher. The AUC was shown to be concentration dependent (123.55 vs. 246.05 at 10 and $20 \mathrm{mg} / \mathrm{kg}$ ) according to the administered dose.

The calculated withdrawal times by applying an official MRL of $0.1 \mu \mathrm{g} / \mathrm{g}$ [29] were 10 days ( $99 \%$ statistical tolerance limit, rounded up to) when $10 \mathrm{mg} / \mathrm{kg}$ of TT was injected at $22{ }^{\circ} \mathrm{C}$. Because of the variability in drug excretion, especially with temperature, a rule of thumb called degree days has been advocated for estimating the required withdrawal time in fish, a poikilothermal animal [33]. It is calculated by adding the mean daily water temperatures (measured in degrees centigrade) for the total number of days measured [1]. Hence, the withdrawal time will be 220 degree days. These data suggest that TT from drug residues will be reduced to ensure reasonable safety for consumers. Unfortunately, there are currently no data on the residual concentrations of TT in all edible fish species, so a sufficient comparison cannot be made.

It is well recognized that macrolides antibiotics as a class exert their activity in parallel with the time length over which tissue concentrations are maintained above the effective level, e.g., MIC [34]. They are so-called 'time-dependent antibiotics'. Thus, the best therapeutic effects will be expected only when blood levels are sustained for a certain time period by repeated administrations if an oral route is chosen. Achieving the temporary effective concentration is likely to result in a compromised effect in treatment [35]. However, 
in a previous study, a weak concentration-dependent killing effect of tylosin was reported, unlike the general characteristics of the macrolide antibiotics [14,36]. Temporary effective concentrations can usually guarantee antibacterial efficacy in the case of TT. This unique property will make TT a good candidate for an IM injection route.

The clinical efficacy of antibiotics against their target pathogens can be predicted by $\mathrm{PK} / \mathrm{PD}$ indices, including $\mathrm{C}_{\max } / \mathrm{MIC}, \mathrm{T}>\mathrm{MIC}$, and AUC/MIC values. A $\mathrm{C}_{\max } / \mathrm{MIC}$ ratio greater than 10 is considered the indicator of activity for concentration-dependent antibiotics [37]. TT, with a partially concentration-dependent effect, was found to satisfy the $\mathrm{C}_{\max } / \mathrm{MIC}_{90}$ values for the two test strains (higher than 10.76, Table 4). For time-dependent antibiotics, such as TT, when a threshold concentration of about four times the MIC is reached, T > MIC is a vital pharmacokinetic and pharmacodynamic factor that determines the in vivo effectiveness of TT and needs to be monitored accordingly [34,38]. In addition, AliAbadi and Lees [39] proposed that the maximum serum drug concentration should be at least twice the MIC for pathogenic microorganisms. Our results demonstrated that large $\mathrm{T}>\mathrm{MIC}_{90}$ values and $\mathrm{AUC}_{0 \text {-inf }} / \mathrm{MIC}_{90}$ were obtained for $S$. iniae and S. parauberis isolates after single IM injection of TT at both 10 and $20 \mathrm{mg} / \mathrm{kg}$ to olive flounder (Table 4). The time period with the serum TT concentration exceeding $\mathrm{MIC}_{90}\left(\mathrm{~T}>\mathrm{MIC}_{90}\right)$ obtained for $S$. parauberis lasted for $44 \mathrm{~h}$ after single IM injection at $10 \mathrm{mg} / \mathrm{kg}$, and S. iniae lasted about 20 more hours (Figure 2 and Table 4). These PK/PD indices support the conclusion that TT is bactericidal against Streptococcus.

\section{Conclusions}

This study has shown the beneficial pharmacokinetic profile, including the bioavailability, of an injectable TT formulation in P. olivaceus and suggested an estimate of its withdrawal time after single IM administration. In addition, clinical parameters were established by examining the PK/PD relationships using MICs of clinical Streptococcus isolates. These data form an important foundation for optimal use of TT as a treatment for systemic infection in P. olivaceus and this provides valuable information for establishing scientific and effective treatment regimens.

Author Contributions: Conceptualization, J.-H.L.; methodology, J.-H.L. and G.W.K.; validation, J.-H.L. and G.W.K.; formal analysis, J.S.S.; investigation, J.-H.L. and G.W.K.; resources, M.-G.K.; writing-original draft preparation, J.-H.L.; writing—review and editing, J.S.S. and J.-H.L.; visualization, J.-H.L.; supervision, J.S.S.; project administration, M.-G.K.; funding acquisition, M.-G.K. and J.S.S. All authors have read and agreed to the published version of the manuscript.

Funding: This research was funded by the National Institute of Fisheries Science, grant number R2020060; the Ministry of Oceans and Fisheries, grant number P2020010.

Institutional Review Board Statement: This study followed the protocol approved by the Institutional Animal Care and Use Committee (IACUC, Fish Study Protocol NIFS-2019-3) from the National Institute of Fisheries Science (NIFS).

Informed Consent Statement: Not applicable.

Data Availability Statement: All data are contained within the article. Please contact first author and the corresponding author for additional data requests.

Acknowledgments: We would like to thank Park Kwan Ha for English language editing.

Conflicts of Interest: The authors declare no conflict of interest.

\section{References}

1. Noga, E.J. Fish Disease: Diagnosis and Treatment; John Wiley \& Sons Publications: Ames, IA, USA, 2010.

2. Soo, J.S.; Kwon, M.G.; Hwang, J.Y.; Hwang, S.D.; Kim, D.H.; Bae, J.S.; Park, K.H.; Lee, J.H. Estimation of pharmacological properties of ceftiofur, an injectable cephalosporin antibiotic, for treatment of streptococcosis in cultured olive flounder Paralichthys olivaceus. Aquac. Res. 2021, 52, 831-841. [CrossRef]

3. NIFS. National Institute of Fisheries Science. 2020. Available online: http://www.nfqs.go.kr/hpmg/adms/actionAdmsForm.do (accessed on 28 July 2021). 
4. Prescott, J.F.; Baggot, J.D. Antimicrobial Therapy in Veterinary Medicine; Iowa State University Press: Ames, IA, USA, 1993.

5. Brisson-Noël, A.; Trieu-Cuot, P.; Courvalin, P. Mechanism of action of spiramycin and other macrolides. J. Antimicrob. Chemother. 1988, 22, 13-23. [CrossRef]

6. Prescott, J.F.; Baggot, J.D. Antimicrobial Therapy in Veterinary Medicine; Blackwell Scientific Publications: Oxford, UK, 1988.

7. Gingerich, D.A.; Baggot, J.D.; Kowalski, J.J. Tylosin antimicrobial activity and pharmacokinetics in cows. Can. Vet. J. 1977, 18, 96.

8. Hannan, P.C.T.; Bhogal, B.S.; Fish, J.P. Tylosin tartrate and tiamutilin effects on experimental piglet pneumonia induced with pneumonic pig lung homogenate containing mycoplasmas, bacteria and viruses. Res. Vet. Sci. 1982, 33, 76-88. [CrossRef]

9. Joo, M.S.; Hwang, S.D.; Choi, K.M.; Kim, Y.J.; Hwang, J.Y.; Kwon, M.G.; Jeong, J.M.; Seo, J.S.; Lee, J.H.; Lee, H.C.; et al. Application of tylosin antibiotics to olive flounder (Paralichthys olivaceus) infected with Streptococcus parauberis. Fish. Aquat. Sci. 2020, 23, 1-18. [CrossRef]

10. Baggot, J.D. Principles of drug distribution. Aust. Vet. J. 1974, 50, 111-119. [CrossRef] [PubMed]

11. Hamill, R.L.; Haney, M.E., Jr.; Stamper, M.; Wlley, P.F. Tylosin, a New Antibiotic: II. Isolation, Properties, and Preparation of Pesmycosin, a Microbiologically Active Degradation Product. Antibiot. Chemother. 1961, 11, 328-334.

12. Abu-Basha, E.A.; Al-Shunnaq, A.F.; Gehring, R. Comparative pharmacokinetics and bioavailability of two tylosin formulations in chickens after oral administration. J. Hell. Vet. Med. Soc. 2012, 63, 159-166. [CrossRef]

13. Atef, M.; Youssef, S.A.; Atta, A.H.; El-Maaz, A.A. Disposition of tylosin in goats. Br. Vet. J. 1991, 147, 207-215. [CrossRef]

14. Elazab, S.T.; Elshater, N.S.; Hashem, Y.H.; Park, S.C.; Hsu, W.H. Pharmacokinetics, tissue residues, and ex vivo pharmacodynamics of tylosin against Mycoplasma anatis in ducks. J. Vet. Pharmacol. Ther. 2020, 43, 57-66. [CrossRef]

15. Litterio, N.J.; Calvinho, L.F.; Flores, M.M.; Tarabla, H.D.; Boggio, J.C. Microbiological screening test validation for detection of tylosin excretion in milk of cows with low and high somatic cell counts. J. Vet. Med. 2007, 54, 30-35. [CrossRef] [PubMed]

16. Prats, C.; El Korchi, G.; Francesch, R.; Arboix, M.; Pérez, B. Disposition kinetics of tylosin administered intravenously and intramuscularly to pigs. Res. Vet. Sci. 2002, 73, 141-144. [CrossRef]

17. Saurit, A.R.; Rubio, M.; Baroni, E.; San Andrés, M.; Sánchez, S.; Boggio, J.C. Some comparative aspects of the pharmacokinetics of tylosin in buffaloes and cattle. Vet. Res. Commun. 2002, 26, 49-54. [CrossRef]

18. Taha, A.A.; Elsheikh, H.A.; Khalafalla, A.E.; OSMAN, I.A.; Abdullah, A.S. Disposition kinetics of tylosin administered intravenously and intramuscularly in desert sheep and Nubian goats. Vet. J. 1999, 158, 210-215. [CrossRef] [PubMed]

19. Smith, P.R.; Le Breton, A.; Horsberg, T.E.; Corsin, F. Guidelines for Antimicrobial Use in Aquaculture. Guide to Antimicrobial Use in Animals; Blackwell Publishing: Oxford, UK, 2008.

20. Soltani, M.; Shanker, S.; Munday, B.L. Chemotherapy of Cytophaga/Flexibacter-like bacteria (CFLB) infections in fish: Studies validating clinical efficacies of selected antimicrobials. J. Fish Dis. 1995, 18, 555-565. [CrossRef]

21. MFDS. Korea Food Standards Codex. Ministry of Food and Drug Safety. 2020. Available online: http:/ /www.foodsafetykorea.go. $\mathrm{kr} /$ foodcode/01_01.jsp (accessed on 28 July 2021).

22. Commission Decision 2002/657/EC (12 August 2002). Implementing Council Directive 96/23/EC concerning the Performance of Analytical Methods and the Interpretation of Results. Available online: https://op.europa.eu/en/publication-detail/-/ publication/ed928116-a955-4a84-b10a-cf7a82bad858/language-en (accessed on 28 July 2021).

23. Zhang, Y.; Huo, M.; Zhou, J.; Xie, S. PKSolver: An add-in program for pharmacokinetic and pharmacodynamic data analysis in Microsoft Excel. Comput. Methods Programs Biomed. 2010, 99, 306-314. [CrossRef]

24. National Committee for Clinical Laboratory Standards Institute. Methods for Dilution Antimicrobial Susceptibility Tests for Bacteria That Grow Aerobically; National Committee for Clinical Laboratory Standards Institute: Wayne, PA, USA, 2014.

25. Lees, P.; Pelligand, L.; Illambas, J.; Potter, T.; Lacroix, M.; Rycroft, A.; Toutain, P.L. Pharmacokinetic/pharmacodynamic integration and modelling of amoxicillin for the calf pathogens Mannheimia haemolytica and Pasteurella multocida. J. Vet. Pharmacol. Ther. 2015, 38, 457-470. [CrossRef]

26. Park, J.Y.; Awji, E.G.; Suh, J.W.; Park, S.C. Pharmacokinetics, pharmacokinetic-pharmacodynamic relationship, and withdrawal period of amoxicillin sodium in olive flounder (Paralichthys olivaceus). Xenobiotica 2016, 46, 522-529. [CrossRef]

27. CVMP; EMEA. Note for Guidance; Approach towards Harmonisation of Withdrawal Periods; EMEA/CVMP/036/95 Final; Committee for Veterinary Medicinal Products and The European Agency for the Evaluation of Medicinal Products: London, UK, 1996. Available online: https://www.ema.europa.eu/en/documents/scientific-guideline/note-guidance-approach-towardsharmonisation-withdrawal-periods_en.pdf (accessed on 28 July 2021).

28. EMEA. Note for Guidance on Approach towards Harmonization of Withdrawal Periods for Meat-Updated Application Software; EMEA/CVMP/563/02; The European Agency for the Evaluation of Medicinal Products Veterinary Medicines and Inspections: London, UK, 2002. Available online: https://www.ema.europa.eu/en/documents/scientific-guideline/note-guidanceapproach-towards-harmonisation-withdrawal-periods-updated-application-software_en.pdf (accessed on 28 July 2021).

29. CVMP. Tylosin (Extension to All Food Producing Species). Summary Report (5). EMEA/MRL/829/02-Final; European Agency for the Evaluation of Medicinal Products: London, UK, 2002. Available online: https://www.ema.europa.eu/en/documents/mrlreport/tylosin-extension-all-food-producing-species-summary-report-5-committee-veterinary-medicinal_en.pdf (accessed on 28 July 2021). 
30. FDA Guidance. Guidance for Industry: Bioanalytical Method Validation. Department of Health and Human Services, Food and Drug Administration, Center for Drug Evaluation and Research (CDER), Center of Veterinary Medicine (CVM). 2018. Available online: https:/ / www.fda.gov / files/drugs/published/Bioanalytical-Method-Validation-Guidance-for-Industry.pdf (accessed on 28 July 2021).

31. Riviere, J.E. Absorption, distribution, metabolism, and elimination. J. Vet. Pharmacol. Ther. 2009, 9, 11-46.

32. Shaddad, S.A.; Hassan, S.A.; El Tayeb, I.B.; Omer, M.A.; Nour, A.O.M.; Al-Nazawi, M.H.; Homeida, A.M. Pharmacokinetics of tylosin in desert sheep after intramuscular injection. Res. J. Pharm. 2007, 1, 19-22.

33. Debuf, Y. The veterinary formulary handbook of medicines used in veterinary practice. J. S. Afr. Vet. Assoc. 1991, 62, 181. [CrossRef]

34. Levison, M.E.; Levison, J.H. Pharmacokinetics and pharmacodynamics of antibacterial agents. Infect. Dis. Clin. 2009, 23, 791-815. [CrossRef] [PubMed]

35. Martinez, M.; Toutain, P.-L.; Walker, R.D. The Pharmacokinetic Pharmacodynamic (PK/PD) Relationship of Antimicrobial Agents and Its Importance in Veterinary Medicine; John Wiley \& Sons Publications: Blackwell, Oxford, UK, 2006.

36. Huang, L.; Zhang, H.; Li, M.; Ahmad, I.; Wang, Y.; Yuan, Z. Pharmacokinetic-pharmacodynamic modeling of tylosin against Streptococcus suis in pigs. BMC Vet. Res. 2018, 14, 1-11. [CrossRef] [PubMed]

37. Toutain, P.L.; del Castillo, J.R.; Bousquet-Mélou, A. The pharmacokinetic-pharmacodynamic approach to a rational dosage regimen for antibiotics. Res. Vet. Sci. 2002, 73, 105-114. [CrossRef]

38. Nielsen, E.I.; Friberg, L.E. Pharmacokinetic-pharmacodynamic modeling of antibacterial drugs. Pharmacol. Rev. 2013, 65, 1053-1090. [CrossRef] [PubMed]

39. AliAbadi, F.S.; Lees, P. Antibiotic treatment for animals: Effect on bacterial population and dosage regimen optimisation. Int. J. Antimicrob. Agents 2000, 14, 307-313. [CrossRef] 